FROM THE

EDITOR-IN-CHIEF

\title{
Keeping Pace with Change
}

If there is one watchword for pharmaceutical innovation it is "change." Keeping pace with dramatic technological and scientific advances in drug discovery and development and adapting to the ever-changing regulatory, political, legal, and social climate for innovation represent significant challenges for all those involved in the process of bringing new medicines to market.

So, too, the Drug Information Journal is changing. It is changing to meet the challenges created by the growing demands on drug developers, regulators, policy makers, and academics for insight and information. You are holding the evidence of that change in your hands. I thought it would be useful to point out some of these changes and explain why we made them.

First, we have adopted a larger physical format, which will put the DIJ in line with other major scientific and medical journals. The Journal will now fit in more easily with your existing filing systems.

Second, each article in the issue is now listed on the cover, making it possible for you to identify the articles of greatest interest before you even open the issue.

Third, the DIJ will now be printed in four colors throughout, including the cover. This will enable us to present more exciting and useful graphics. Color will also help you better differ- entiate data within graphs and charts and absorb the information presented with greater ease and precision.

Fourth, the layout style throughout has been updated, again to improve the organization of each article and to provide visual cues to facilitate your reading. The first page of each article, for instance, will feature an abstract in a shaded block, which will summarize the article and provide you with an overview of its main points.

Less obvious, but no less important than the changes we've made to format and content organization, are the improvements we've made to administrative processes and editorial board procedures. For example, we've updated and formalized the criteria used by our manuscript reviewers, to assist in the review process and to provide consistent standards for the determination of what is published. The interest areas of DIA members are considerable. Whereas the editorial board and staff of the Journal continue to seek a broad range of articles that best address the interests and information of our readership, you, the reader, need to be assured that these articles meet the highest standards for scholarship and value.

As the official publication of the Drug Information Association, the Drug Information Journal reflects the interests of DIA members around 
the world who are involved in the discovery, development, regulation, utilization, and marketing of pharmaceuticals and related products. The Journal is a work in progress. Over the coming year there will be further changes made to the organization of articles within each issue and to administrative processes. It is our hope that these changes will increase the value of the Journal to its readership. Should you have any suggestions of ways that we can better serve your need for timely and incisive analysis and commentary on trends and developments in pharmaceutical innovation, don't hesitate to let us know.

Kenneth I Kaitin, PhD

Editor-in-Chief 